University of Nebraska - Lincoln

DigitalCommons@University of Nebraska - Lincoln

Papers in the Earth and Atmospheric Sciences

Earth and Atmospheric Sciences, Department

$4-2003$

\title{
Field Study of Hydraulic Conductivity in a Heterogeneous Aquifer: Comparison of Single-Borehole Measurements Using Different Instruments
}

Vitaly A. Zlotnik

University of Nebraska-Lincoln, vzlotnik1@unl.edu

Brian R. Zurbuchen

Nebraska Department of Environmental Quality

Follow this and additional works at: https://digitalcommons.unl.edu/geosciencefacpub

Part of the Earth Sciences Commons

Zlotnik, Vitaly A. and Zurbuchen, Brian R., "Field Study of Hydraulic Conductivity in a Heterogeneous Aquifer: Comparison of Single-Borehole Measurements Using Different Instruments" (2003). Papers in the Earth and Atmospheric Sciences. 154.

https://digitalcommons.unl.edu/geosciencefacpub/154

This Article is brought to you for free and open access by the Earth and Atmospheric Sciences, Department of at DigitalCommons@University of Nebraska - Lincoln. It has been accepted for inclusion in Papers in the Earth and Atmospheric Sciences by an authorized administrator of DigitalCommons@University of Nebraska - Lincoln. 


\title{
Field study of hydraulic conductivity in a heterogeneous aquifer: Comparison of single-borehole measurements using different instruments
}

\author{
Vitaly A. Zlotnik and Brian R. Zurbuchen ${ }^{1}$ \\ Department of Geosciences, University of Nebraska at Lincoln, Lincoln, Nebraska, USA
}

Received 29 April 2002; revised 23 October 2002; accepted 24 February 2003; published 22 April 2003.

[1] This field study compares three techniques for estimating the vertical distribution of horizontal hydraulic conductivity $K_{r}$ in a heterogeneous aquifer and evaluates possible support volume effects. The dipole flow test (DFT), multilevel slug test (MLST), and borehole flowmeter test (BFT) are based on different kinematic flow structures and the shape and the size of the support volumes. The experiment design employed an identical characteristic linear scale for all tests. Vertical profiles of $K_{r}$ ranging up to $260 \mathrm{~m} /$ day from tested wells in an alluvial aquifer exhibit a strong correlation in spite of the differences between test hydraulics. Results suggest that tested screen length is an important indicator of the averaging mechanism for hydraulic tests. Correlation between the DFT and MLST is especially strong. Correlation between data from the BFT and other tests is not as strong due to the absence of a distinct physical vertical scale, among other factors. The differences between the tests are discussed using the concept of a weighting function associated with the magnitude of instantaneous local velocity. INDEX TERMS: 1829 Hydrology: Groundwater hydrology; 1894 Hydrology: Instruments and techniques; 5114 Physical Properties of Rocks: Permeability and porosity; 5194 Physical Properties of Rocks: Instruments and techniques; KEYWORDS: Hydraulic conductivity, dipole-flow test, slug test, borehole flowmeter test, instruments, support volume

Citation: Zlotnik, V. A., and B. R. Zurbuchen Field study of hydraulic conductivity in a heterogeneous aquifer: Comparison of single-borehole measurements using different instruments, Water Resour. Res., 39(4), 1101, doi:10.1029/2002WR001415, 2003.

\section{Introduction}

[2] The quantity and quality of hydraulic conductivity $(K)$ data in heterogeneous aquifers is an issue of primary importance in subsurface hydrology. The number of $K$ measurements rarely reaches $10^{3}$ points even in major academic and applied studies, and there is skepticism about adequacy of these databases for accurate prediction of subsurface flow and transport [e.g., Eggleston and Rojstacher, 2000]. To circumvent this difficulty and to maximize the amount of information available for subsurface characterization, two pragmatic approaches are currently used.

[3] The first approach combines data from several techniques for hydraulic aquifer characterization [Brace, 1984; Clauser, 1992; Schulze-Makuch and Cherkauer, 1998; Zlotnik et al., 2000]. This introduces significant conceptual and practical difficulties because different testing methods "interrogate" different volumes of the heterogeneous aquifer adjacent to the instrument. Therefore the resulting $K$ estimates and statistics (e.g., mean, variance, correlation scale, etc.) differ considerably even in weakly heterogeneous aquifers [e.g., Hess et al., 1992, Table 2]. The ramifications of this uncertainty are important, because the variance and correlation scale in $\ln K$ determine the macro-

\footnotetext{
${ }^{1}$ Now at Nebraska Department of Environmental Quality, Lincoln, Nebraska, USA.

Copyright 2003 by the American Geophysical Union.
} 0043-1397/03/2002WR001415\$09.00 scale aquifer transport properties [e.g., Dagan, 1989]. Reconciliation of various data sets is important for improving the site characterization.

[4] The second approach complements the usually sparse hydraulic testing data with nonintrusive subsurface geophysical methods [e.g., Hyndman and Gorelick, 1996; Hubbard and Rubin, 2000]. Conditioning of the geophysical data based on hydraulic "point" measurements of $K$ allows one to develop a more comprehensive data set of aquifer $K$. While this approach holds promise, the role of each individual hydraulic measurement becomes even more important.

[5] To reconcile differences between various hydraulic testing techniques, one must address a number of fundamental questions. For example, what characteristic volume should be associated with a "point" $K$ estimate? Which hydraulic testing technique yields a "true" point estimate?

[6] In heterogeneous formations, any point $K$ estimate is necessarily a result of applying the steady state or transient model of groundwater flow in locally uniform anisotropic media to the heterogeneous media near the measuring instrument. This procedure introduces a physical averaging that is determined by both the aquifer and the instrument properties [e.g., Baveye and Sposito, 1984; Cushman, 1984]. Dimensional analysis of the boundary value problem of groundwater flow indicates that this estimate depends on the linear scales of both the instrument and heterogeneity, such as the correlation scale of $K$ [Desbarats, 1992; Indelman and Zlotnik, 1997]. Due to the elliptic or parabolic type 
of the groundwater flow equations, the heterogeneity of $K$ in the infinite volume contributes to the instrument estimate of $K$. However, remote zones contribute less to this estimate, and it is commonly assumed that their influence is negligible. The finite volume adjacent to the instrument is called the "support volume". Techniques with different kinematic flow structures and support volumes yield different $K$ estimates; i.e. the point $K$ estimate and the support volume are interrelated. However, a general and robust theory for evaluation of the support volume for existing methods is still in development [e.g., Beckie, 2001].

[7] The averaging mechanism is not necessarily linear [Desbarats, 1994]. However, the linear averaging and associated weighting functions are intuitive and have certain operational advantages [Desbarats, 1992, 1993; Beckie, 1996, 2001]. Successful examples include models of pumping or recirculation tests in a heterogeneous two-dimensional aquifer [Desbarats, 1992, 1993], where the "inversepower-distance" form of the weighting functions proved to be effective tool for finding the equivalent transmissivity. This result corresponds well to theoretical studies by Oliver [1990, 1993], who found a similar functional form of the sensitivity coefficients while investigating the averaging procedures in two-dimensional heterogeneous fields. Beckie and Wang [1994] and Beckie [2001] identified weighting functions for two-dimensional flow using numerical experiments. Assuming a perfectly stratified aquifer, Indelman and Zlotnik [1996] estimated the equivalent $K$ for several more realistic types of hydraulic tests with three-dimensional flow, but these results have not been applied to laboratory or field data interpretation.

[8] Zlotnik and Ledder [1996] and Tartakovsky et al. [2000] studied instruments that are used for field and laboratory $K$ estimation and suggested that the weighting function is associated with the magnitude of local velocity. The functional form of the weighting coefficients (inverse-powerdistance form) explored by Desbarats [1992, 1993] may also be related to velocity magnitude as suggested by numerical computations [see Desbarats, 1992, Figure 1; Desbarats, 1993, Figure 6]. Recently, Molz et al. [2000] hypothesized that a squared velocity magnitude could adequately represent the weighting function in the case of nonuniform flow.

[9] Experimental studies of the support volume are very rare. A unique laboratory study by Tidwell et al. [1999] produced an empirical weighting function using data from multiscale air-injection tests on large samples $(\approx 1 \mathrm{~m}$ in linear size). However, to our knowledge, evaluation of the support volume or weighting functions has not been applied to field methods of $K$ characterization. For field methods, the assessment of the support volumes and averaging mechanisms in the absence of general theory is even more complex [Zlotnik et al., 2000]. This assessment must start with the identification of the test parameters that are reliable predictors of similarity between the results of different testing techniques in heterogeneous aquifers.

[10] Various hydraulic tests utilize different kinematic flow structures, and therefore different shapes and sizes of the support volume. Published analyses of the scale effects between various field techniques are abundant [see Zlotnik et al., 2000]. However, direct and consistent comparison of the data between several hydraulic tests applied within the same well has not yet been published. Previous studies typically investigated a single hydraulic testing technique in combination with borehole geophysical methods [e.g., Molz et al., 1994; Hvilshøj et al., 2000].

[11] We use a unique combination of several singleborehole hydraulic tests as the experimental method and the tested screen interval as a characteristic scale for comparison of these tests. The tests used are the slug test in multilevel format (MLST [Melville et al., 1991, Zlotnik and McGuire, 1998a, 1998b; Zurbuchen et al., 2002]), the borehole flowmeter test (BFT [e.g., Molz et al., 1989, Rehfeldt et al., 1989]), and the steady state dipole flow test (DFT [Kabala, 1993; Zlotnik and Ledder, 1996; Zlotnik and Zurbuchen, 1998; Zlotnik et al., 2001]).

[12] The objectives of this paper are to compare the aforementioned three hydraulic single-borehole techniques for estimation of hydraulic conductivity $\left(K_{r}\right)$ in a heterogeneous aquifer and to evaluate the possible support volume effects. Our approach involves the following steps: (1) consistent application of three single-borehole hydraulic testing methods that have different averaging mechanisms but similar linear characteristics; (2) interpretation of the data to obtain vertical profiles of $K_{r}$; (3) assessment of the correlation between $K_{r}$ profiles obtained from these techniques; and (4) qualitative analysis of the averaging mechanism associated with the spatial distribution of velocity magnitude for the three different experimental methods.

\section{Methods}

[13] The selected hydraulic testing methods, MLST, DFT, and BFT, have drastically different kinematic flow structures and support volumes. Detailed treatment of MLST [Zlotnik and McGuire, 1998a, 1998b; Zurbuchen et al., 2002] and DFT [Zlotnik and Zurbuchen, 1998; Zlotnik et al., 2001] was given in our previous publications, and the BFT was described in detail by Molz et al. [1989, 1994] and Rehfeldt et al. [1989]. This section highlights only the specifics of the theory, data acquisition, and interpretation that are relevant to our study.

[14] Interpretations of single-borehole hydraulic tests are weakly sensitive to the local aquifer anisotropy $a=\left(K_{r} / K_{z}\right)^{1 / 2}$ where $K_{z}$ is vertical hydraulic conductivity [Streltsova, 1988 , p. 20; Butler, 1997, p. 98]. In addition, there is significant evidence from laboratory and field tests, that $a$ is on the order of one $(\approx 1)$ at the scale of our single-borehole tests [e.g., Zlotnik, 1994; Sutton et al., 2000; Zlotnik et al., 2001]. Therefore our analysis assumed $a=1$ for all methods. The effect of $a>1$ is assessed in a sequel.

[15] Field studies of skin effect in single-borehole tests saw little progress after Taylor et al. [1990], Taylor and Molz [1990], or Boman et al. [1997]. Limited options of skin control include the selection of an appropriate drilling method (type, tool diameter, and circulation fluid), method of well completion (using the natural collapse of the aquifer material instead of a gravel pack and proper well development) and the use of geotextile rings [Ptak and Teutsch, 1994]. Below, we use the first two options and assume negligible skin effects in the data interpretation.

\subsection{Steady State Dipole Flow Test (DFT)}

[16] The DFT involves using a three-packer system (Figure 1a) to isolate two screened sections (chambers) in 


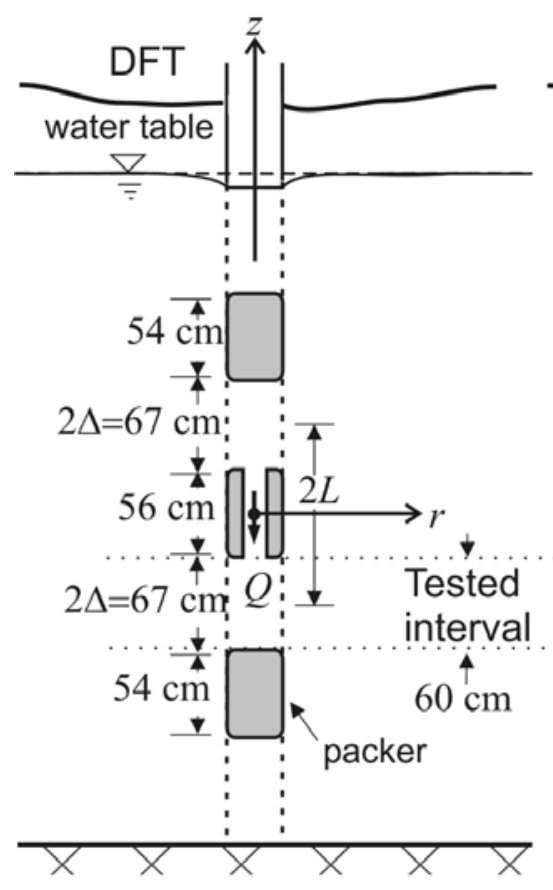

(a)

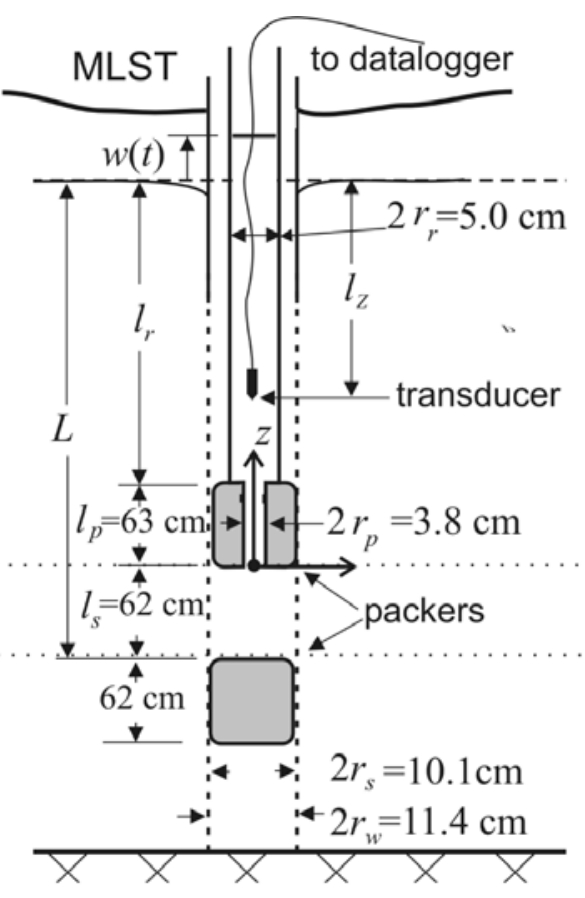

(b)

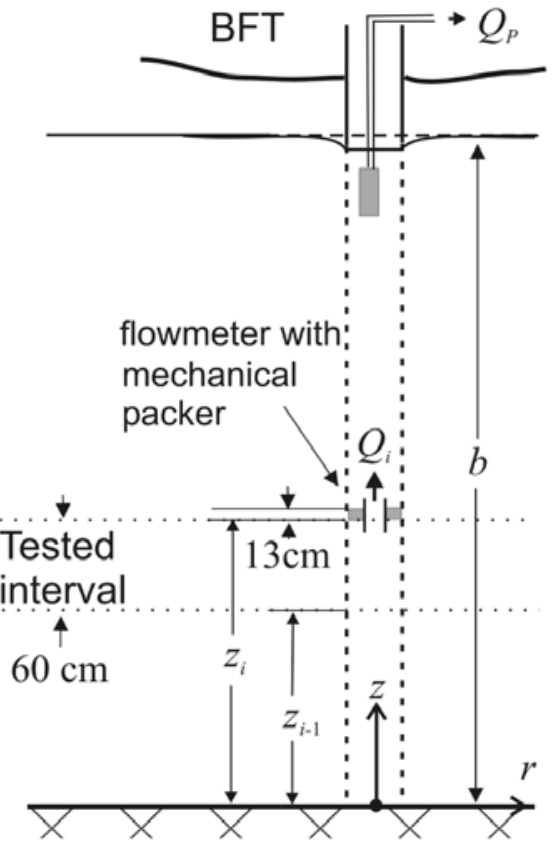

(c)

Figure 1. Schematic diagrams of the single-borehole tests in the same borehole for a given tested interval: (a) DFT, (b) MLST, and (c) BFT, pumping rate $Q_{p}=82 \mathrm{~m}^{3} /$ day.

a single well with a continuous screen [Kabala, 1993; Zlotnik and Zurbuchen, 1998]. A small submersible pump located in the upper (extraction) chamber transfers water from the aquifer at a known recirculation rate $Q$ through the central packer, into the lower (injection) chamber, where it is reinjected into the aquifer. This invokes a recirculatory flow in the near-borehole zone. Measurements of head changes in the dipole probe (DP) chambers by two pressure transducers are used to estimate $K_{r}$, which is characteristic of the zone of intensive recirculation. Absence of drawdown above and below DP monitored by additional transducers serves as an indication of a proper packer seal.

\subsubsection{Theory}

[17] Using steady state flow equations for analysis of the kinematic flow structure near the DP in a homogeneous anisotropic aquifer, Zlotnik and Ledder [1994, 1996] found that the most intensive groundwater flow occurs in the immediate vicinity of the DP, and the effect of the horizontal boundaries on chamber drawdown is negligible. This greatly simplifies the DFT interpretation. In the case of a uniform infinite aquifer, head changes in the upper chamber $\left(S_{U}\right)$ and the lower chamber $\left(S_{L}\right)$ have equal absolute values and opposite signs:

$$
S_{U}=-S_{L}=\frac{Q}{K_{r} \Delta} f_{i}
$$

where the shape factor $f_{i}$ is calculated using the following equation:

$$
f_{i}=\frac{\rho_{w}}{16 \pi \Delta}\left[-\left.\phi\right|_{q_{++}} ^{p_{++}}+\left.\phi\right|_{q_{+-}} ^{p_{+-}}+\left.\phi\right|_{q_{-+}} ^{p_{-+}}-\left.\phi\right|_{q} ^{p}\right]
$$

where $p_{ \pm \pm}=(L+\Delta \pm L \pm \Delta) / \rho_{w}, q_{ \pm \pm}=(L-\Delta \pm L \pm \Delta) / \rho_{w}$, $\rho_{w}=r_{w} / a, r_{\mathrm{w}}$ is the well radius, $\Delta$ is the chamber half-length,
$L$ is the half-distance between the chambers centers, and $\phi(x)=x \ln \left(x+\sqrt{x^{2}+1}\right)-\sqrt{x^{2}+1},\left.\quad \phi\right|_{q} ^{p}=\phi(p)-\phi(q)$ [e.g., Zlotnik et al., 2001].

\subsubsection{Localization of Measurements}

[18] Zlotnik and Ledder [1994, 1996] investigated the size of the recirculation zone in the vicinity of the DP in a uniform aquifer and found that about $90 \%$ of the flow is concentrated laterally in the zone on the order of five DP lengths. In heterogeneous aquifers, the magnitude of drawdown differs between chambers, which means that individual chambers are sensitive to the heterogeneity and that the support volume is determined by the length of the screened section [Zlotnik and Zurbuchen, 1998; Zlotnik et al., 2000, 2001].

\subsubsection{Transient Effects}

[19] Analyses of the DFT [Zlotnik and Ledder, 1994, 1996] and field data in highly permeable alluvial aquifers [Zlotnik and Zurbuchen, 1998; Hvilshøj et al., 2000] indicate that head stabilization occurs rapidly (within a few seconds to minutes). Therefore the steady state version of the DFT is appropriate for estimating hydraulic conductivity $K_{r}$ [Zlotnik and Zurbuchen, 1998; Zlotnik et al., 2000, 2001].

\subsubsection{Data Interpretation}

[20] Equation (1) can be used to estimate an apparent local $K_{r}$ value in the vicinity of the DP if the value of anisotropy $a$ is available. One interpretation is based on the assumption that the aquifer is homogeneous in the vicinity of the DP. In this case, the head difference between chambers $\Delta h=S_{U}+\left|S_{L}\right|$ can be used to estimate $K_{r}$ [Zlotnik and Zurbuchen, 1998].

$$
K_{r, \Delta h}=\frac{2 Q}{\Delta \cdot \Delta h} f_{i}
$$


This so-called "head difference" interpretation [Zlotnik et al., 2001] yields a $K_{r}$ estimate that is characteristic of the DFT support volume, which extends radially and vertically on the order of several DP lengths.

[21] In heterogeneous aquifer, the magnitudes of head changes in chambers can be different [Zlotnik and Zurbuchen, 1998; Zlotnik et al., 2001]. In such cases, the DFT can yield a higher resolution in $K_{r}$ by separately interpreting drawdown in each chamber. Estimates of $K_{r}$ that are representative of the zones adjacent to the upper chamber $\left(K_{r, U}\right)$ and the lower chamber $\left(K_{r, L}\right)$ are obtained from the "by-chamber" interpretations:

$$
K_{r, U}=\frac{Q}{\Delta \cdot S_{U}} f_{U}, K_{r, L}=\frac{Q}{\Delta \cdot\left|S_{L}\right|} f_{L}
$$

where the shape factors $f_{U}$ and $f_{L}$ depend on hydrogeological setting and DP geometry. Generally, one can use $f_{U}=$ $f_{L}=f_{i}$ from equation (2), when the aquifer boundaries do not affect the DFT (see discussion by Zlotnik et al. [2000, 2001]).

[22] It is evident from equations (3) and (4) that $K_{r, \Delta h}$ is the harmonic mean of the by-chamber estimates $\left(K_{r, U}\right.$ and $\left.K_{r, L}\right)$ in an aquifer of infinite thickness: $K_{r, \Delta h}=2\left(K_{r, U}{ }^{-1}+\right.$ $\left.K_{r, L}{ }^{-1}\right)^{-1}$. Thus $K_{r, \Delta h}$ is weighted more toward the smaller of these estimates as compared to their arithmetic mean.

\subsubsection{Data Acquisition and Instruments}

[23] In this study, an additional pressure transducer was used above the DP to monitor the packer seal. A packer length-to-radius aspect ratio $>10$ was selected to minimize water short-circuiting between the chambers and the rest of the well based on Cole and Zlotnik's [1994] criterion. A test interval of $2 \Delta=67 \mathrm{~cm}$ was used (Figure 1a). DP dimensions $L, \Delta$, and $r_{w}$ were chosen to be consistent with other tests shown on Figure 1.

[24] Flow rate $Q$ is a function of the head difference across the pump and pump speed (controller frequency). This head difference was maintained below $1 \mathrm{~m}$ in all tests. Within this range, the flow rate depends only on the pump controller frequency, and thus a simplified pump performance curve [Zlotnik and Zurbuchen, 1998, Figure 5] was used.

\subsection{Multilevel Slug Test (MLST)}

[25] The use of the MLST in hydrogeological applications is relatively recent [Melville et al., 1991; Zlotnik and McGuire, 1998a, 1998b]. The MLST employs a two-packer system (Figure 1b) to isolate the tested well section. This test involves monitoring water level recovery after an instantaneous water level displacement in the riser pipe attached to the double-packer system. Interpretation of water level recovery yields $K_{r}$. Multiple tests at different elevations yield a vertical profile of $K_{r}(z)$.

\subsubsection{Theory}

[26] Various MLST models consider the well, aquifer, and well-aquifer exchange using the mass and momentum conservation equations; they differ in the analysis of head losses and the degree of nonlinearity [McElwee and Zenner, 1998; Zurbuchen et al., 2002]. The model for water level $w(\tau)$ with initial zero velocity can be formulated as the initial value problem:

$$
w^{\prime \prime}+F w^{\prime}+H w=G, \quad w(0)= \pm w_{0}, \quad w^{\prime}(0)=0,
$$

where $\tau=t\left(g / L_{e}\right)^{1 / 2}$ is dimensionless time, $t$ is dimensional time, $w^{\prime}=d w / d \tau, w_{0}$ is the magnitude of the initial water level displacement (plus and minus signs are used for the falling and rising head tests, respectively), $g=9.81 \mathrm{~m} / \mathrm{s}^{2}, L_{e}$ $=l_{r}+l_{p} r_{r}{ }^{2} / r_{p}{ }^{2}+0.5 l_{p} r_{r}{ }^{2} / r_{s}{ }^{2}$, and $l_{s}, l_{r}, l_{p}, r_{s} \approx r_{w}, r_{r}, r_{p}$ are lengths and radii of the well screen, riser pipe, and the packer pipe (Figure 1b).

[27] The parameters $F, H$, and $G$ are dependent on test geometry, $w$, and $w^{\prime}$ [Zurbuchen et al., 2002]. For small initial displacements, $F \approx F_{0}=r_{r}{ }^{2}\left(g / L_{e}\right)^{1 / 2} /\left(2 K_{r} P l_{s}\right), H \approx 1$, $G \approx 0$, where $P=P\left(\frac{r_{w}}{a b}, \frac{L_{e}}{b}, \frac{l_{s}}{b}\right)$ is the shape factor [see Bouwer and Rice, 1976; Zlotnik, 1994]. The resulting linearized model by Springer and Gelhar [1991] has the following analytical solution:

$$
w(\tau)=\left\{\begin{array}{c}
\mp w_{0}\left(\gamma_{-} e^{\gamma_{+} \tau}-\gamma_{+} e^{\gamma_{-} \tau}\right) /(2 \gamma), \quad F_{0}>2, \\
\mp w_{0} e^{\gamma \tau}(1+\tau), \quad F_{0}=2, \\
\mp w_{0} e^{F \tau / 2}\left[\cos (\gamma \tau)+F_{0} \sin (\gamma \tau) /(2 \gamma)\right], \quad F_{0}<2
\end{array}\right.
$$

where $\gamma=\left|1-F_{0}^{2} / 4\right|^{1 / 2}, \gamma_{ \pm}=-F_{0} / 2 \pm \gamma$.

\subsubsection{Transient Effects}

[28] MLST is an inherently transient technique. The response duration in alluvial aquifers may last from seconds to minutes. Parameter $F_{0}$ determines the response type. Water table behavior is oscillatory when $F_{0}<2$, or $K_{r}>\frac{r_{r}^{2}}{4 l_{s} P}\left(\frac{g}{L_{e}}\right)^{1 / 2}$. Otherwise, the response is monotonic in time $\left(F_{0} \geq 2\right)$. Changes in the riser pipe radius, screen length, and effective length of the water column in the MLST instrument may alter this critical value and the response type.

\subsubsection{Localization of Measurements}

[29] The flow velocities path lines are normal to the screen interval at the early time in the volume of a cylindrical shape. As the head changes with increasing distance from the well, the shape of the support volume resembles an axisymmetric ellipsoid. Guyonet et al. [1993] defined the support volume of the slug test as a cylinder around the tested interval with the confining surface separating the zone with the head changes less than 1$10 \%$ of $w_{0}$. This head-based definition includes the aquifer storativity but ignores the effect of the screen length. Estimates of the support volume based on the Guyonet et al. [1993] definition range from 10 to $10^{4}$ well radii for the common storativity values. This range is too broad to be of practical use, and a more constructive approach is needed.

\subsubsection{Data Interpretation}

[30] The linearized Springer and Gelhar [1991] model involves only one unknown parameter, $K_{r}$, which easily lends itself to identification by matching slug-test field response to one of the type curves (6). The use of nonlinear models can improve this match in high $K_{r}$ zones [e.g., McElwee and Zenner, 1998]. However, refinements of $K_{r}$ are small in the linearity range. In lower $K_{r}$ zones, standard slug test interpretation is still valid [e.g., Bouwer and Rice, 1976].

[31] For data interpretation, the acceleration of the water column was considered within high $K_{r}$ zones. Equations (5) and (6) are written in terms of the water level $w(t)$, whereas the pressure transducer reads the hydraulic head $h_{\mathrm{z}}$ at the 
depth of measurement $l_{\mathrm{z}}$ (Figure 1b). The differential relationship [Springer, 1991; Zurbuchen et al., 2002]:

$$
h_{z}=w+\left(w+l_{z}\right) \frac{d^{2} w}{d t^{2}}
$$

was used to correct the pressure transducer readings.

\subsubsection{Data Acquisition and Instruments}

[32] These have been described previously by Zlotnik and McGuire [1998a, 1998b] and Zurbuchen et al. [2002]. In this study, a tested interval $l_{s}=62 \mathrm{~cm}$ was used (Figure 1b). The packer length-to-radius aspect ratio $>10$ was selected to minimize water short-circuiting between the tested interval and the rest of the well above and below the packers [Cole and Zlotnik, 1994]. The remaining parameters of the system are shown on Figure 1b. The length of the riser pipe $\left(l_{r}\right)$ varied with the depth of the tested interval.

[33] Small $w_{0}$ was used to minimize the nonlinear flow processes [Butler, 1998; Zurbuchen et al., 2002]. The test was replicated using a range of $w_{0}$. Normalized recovery curves $w(t) / w_{0}$ were compared to determine the range for which the Springer and Gelhar [1991] model was valid. In low $K_{r}$ zones, all responses were nonoscillatory and linear.

[34] The early data were inspected for effects of various physical processes associated with well-aquifer hydraulics (e.g. acceleration, turbulence, compressibility) or operational factors (slug initiation method, air release, frequency of data collection, etc.).

\subsection{Borehole Flowmeter Test (BFT)}

[35] The standard methodology for the BFT involves measuring the vertical flow rate inside the well at various depths (Figure 1c). The flow rate at any given elevation is monitored over the entire portion of the screen section below the flowmeter position. Cumulative flow rates are usually measured for ambient flow conditions $(q(z))$ and under pumping conditions $(Q(z))$ [Molz et al., 1990, 1994; Rehfeldt et al., 1989]. The cumulative flow rate under pumping conditions at the top of the aquifer $(z=b)$ is equal to the pump flow rate: $Q_{p}=Q(b)$.

\subsubsection{Theory}

[36] In perfectly stratified aquifers, $K_{r}$ is a function of the vertical coordinate only. In the absence of ambient flow, the equipotentials align vertically and become parallel to the screen in the vicinity of the borehole shortly after pumping starts [Javandel and Witherspoon, 1969]. This applies only to fully penetrating wells. The drawdown in more remote parts of the aquifer may remain transient. From Darcy's equation, the inflow to the well from each distinct $i$ th aquifer layer $\left(\Delta Q_{i}=Q_{i}-Q_{i-1}\right)$ is proportional to $K_{r}$ in the layer $\left(K_{r, i}\right)$. This inflow can be obtained as an incremental value of the cumulative flow rate as the tool is raised from elevation $z_{i-1}$ to elevation $z_{i}$ with an increment $\Delta z_{i}=z_{i}-z_{i-1}$. Rehfeldt et al. [1989] discussed various factors affecting the BFT results (well and screen head losses, skin effects, etc.).

\subsubsection{Transient Effects}

[37] Unlike the DFT or MLST, the BFT employs the quasi-steady conditions of stabilized velocities in the nearborehole zone and transient processes in the far zone. Transient effects in drawdown at a radial distance $r$ in the vicinity of the borehole vanish after $t>(10-100) S_{s} b r^{2} / T$, where $T$ is the aquifer transmissivity and $S_{s}$ is specific storage [Javandel and Witherspoon, 1969; Rehfeldt et al., 1989]. The criterion becomes more restrictive in the pres- ence of the heterogeneity, water table conditions, and largescale anisotropy. However, in many unconsolidated systems it lasts on the order of minutes or hours.

\subsubsection{Localization of Measurements}

[38] Unlike the DFT and MLST, the flow field induced by BFT lacks a vertical linear scale because the groundwater path lines are always normal to the screen interval [Javandel and Witherspoon, 1969]. Therefore the delineation of the support volume is not intuitive. For example, Eggleston et al. [1996, p. 1211] proposed using the transient zone as the support volume. The literature abounds with BFT applications, but the issues of support volume or weighting functions have not yet been addressed.

\subsubsection{Data Interpretation}

[39] Rehfeldt et al. [1989], Molz et al. [1989], Dinwiddie et al. [1999], and Ruud et al. [1999] investigated several assumptions commonly made when interpreting the cumulative flow rate curves: (1) each layer is of a constant thickness $\Delta z_{i},(i=1,2, \ldots) ;(2) K_{r, i}$ is homogeneous within each layer; (3) the flow system in the vicinity of the well is horizontal; (4) the difference between the flow rate in pumping conditions and ambient flow can be assessed at different layers; (5) this difference contributed by each layer due to pumping is proportional to the product of the layer thickness $\Delta z_{i}$ and $K_{r, i} ;$ (6) well losses attributable to each layer can be quantified; and (7) head losses across the borehole flowmeter are negligible.

[40] After dividing the aquifer into uniform layers of thickness $\Delta z_{i}$, the by-layer inflow to the well $\Delta Q_{i}-\Delta q_{i}$ can be found, and the normalized by-layer $K_{r, i}$ can be calculated from these data using

$$
\frac{K_{r, i}}{K_{r, a v e}}=\frac{\left(\Delta Q_{i}-\Delta q_{i}\right) / \Delta z_{i}}{Q_{p} / b}, i=1,2, \ldots
$$

where $K_{r, a v e}=\frac{1}{b} \sum_{i=1}^{n} K_{r, i} \Delta z_{i}$ is the arithmetic mean of $K_{r}$ over the screen length [Molz et al., 1989].

[41] These assumptions were rarely tested in heterogeneous formations [e.g., Rehfeldt et al., 1989; Ruud and Kabala, 1997; Boman et al., 1997; Dinwiddie et al., 1999; Ruud et al., 1999]. However, in the absence of practical alternatives, equation (8) is used routinely.

\subsubsection{Data Acquisition and Instruments}

[42] We used an electromagnetic borehole flowmeter with a $2.54 \mathrm{~cm}$ diameter flow-through channel, a $23-\mathrm{cm}$ long outer orifice [Molz et al., 1994], and a Grundfos ${ }^{\circledR}$ Jet Sub pump operated at a flow rate $82 \mathrm{~m}^{3} /$ day. A flange-type mechanical packer consisting of rubber collars $0.7-\mathrm{cm}$ thick and $13 \mathrm{~cm}$ apart was used to prevent by-pass flow in the borehole (Figure 1c).

\section{Experimental Results}

\subsection{Site and Testing Wells}

[43] The unconfined alluvial aquifer beneath a Management System Evaluation Area site, the Platte River watershed, in Nebraska, was used for testing the instrumentation and field methodologies. This site has been described previously by Zlotnik and McGuire [1998b] and Zlotnik and Zurbuchen [1998] [see also Spalding and Exner, 1980]. The 18-m thick Pleistocene age aquifer consists of sand and gravel, underlain by a 9 to $20 \mathrm{~m}$ thick silt-clay layer. This 
layer was considered an aquiclude for the timescale of the single-borehole tests.

[44] The reverse rotary drilling method (bit diameter $15.2 \mathrm{~cm}$ ) was used without drilling mud to install two wells (wells 14 and 15) spaced $10 \mathrm{~m}$ apart. Both wells were constructed using schedule 40 PVC casing and continuous screen with an inner diameter of $10.2 \mathrm{~cm}$, an outer diameter of $11.4 \mathrm{~cm}$, and a screen slot size of $0.51 \mathrm{~mm}$. This resulted in a borehole annulus of less than $2 \mathrm{~cm}$ and an open screen area of $8 \%$. The flush threaded well screen was $15.2 \mathrm{~m}$ in length and fully penetrated the aquifer, with a short length of screen extending above the water table into the unsaturated zone. Drilling logs indicate the presence of sand and gravel without silt/clay inclusions. The wells were initially developed by pumping at $2.8 \mathrm{l} / \mathrm{s}$ and by surging. The data from several hundred DFTs, MLSTs, and BFTs with higher pumping rates did not indicate any further development during the intensive testing program in 1998-1999.

[45] An important element of the methodology used is that each $60-\mathrm{cm}$ interval was characterized by all three techniques in each well (Figure 1). In the DFT, this interval was investigated three times using both the lower (Figure 1a) and upper chambers, and by centering the DP within this interval. In the MLST, this interval was isolated by packers (Figure 1b). In the BFT, this interval was bounded by two positions of the borehole flowmeter (Figure 1c).

\subsection{DFT Data}

[46] In the sequence of DFTs, the centers for each tested interval were located at various depths using $30 \mathrm{~cm}$ increments. Thus each $60-\mathrm{cm}$ section of the tested well was covered three times: by the upper chamber, by the lower chamber, and by the central packer, which had a length of approximately $60 \mathrm{~cm}$. Thus $K_{r, U}, K_{r, L}$ and $K_{r, \Delta h}$ values at each elevation were obtained using different positions of the DP's center point.

[47] In equation (4), $K_{r, U}$ corresponds to the drawdown induced by water extraction from the upper chamber, and $K_{r, L}$ corresponds to the draw up induced by water injection into the lower chamber. It is apparent that the support volumes for each of these estimates are different. At each tested elevation, $K_{r, \Delta h}$ was estimated using equation (3), which corresponds to the location of the DP center at the midpoint of the screen section that is blocked off by the central packer; such an estimate considers fluid circulation over the larger interchamber zone and represents more averaged $K_{r}$ values. All estimates were obtained assuming isotropic conditions.

[48] Vertical profiles of $K_{r, U}, K_{r, L}$ and $K_{r, \Delta h}$ are shown in Figure 2a for well 14 and in Figure $2 \mathrm{~b}$ for well $15 . K_{r, U}$ and $K_{r, L}$ profiles are very similar in spite of differences in support volume shape. They exhibit greater variability than the $K_{r, \Delta h}$ profile; for example, the $K_{r, \Delta h}$ profile has a smaller spread of peaks. As discussed in section 2 , the head difference interpretation smoothes out the vertical variations of $K_{r}$. Therefore the by-chamber method of data interpretation provides enhanced resolution of the heterogeneous $K_{r}$.

[49] Correlation of $K_{r, U}$, and $K_{r, L}$ estimates is displayed in scatterplots and linear regression of $K_{r, U}$, on $K_{r, L}$ estimates in Figure $3 \mathrm{a}$ for well 14 and in Figure $3 \mathrm{~b}$ for well 15. The
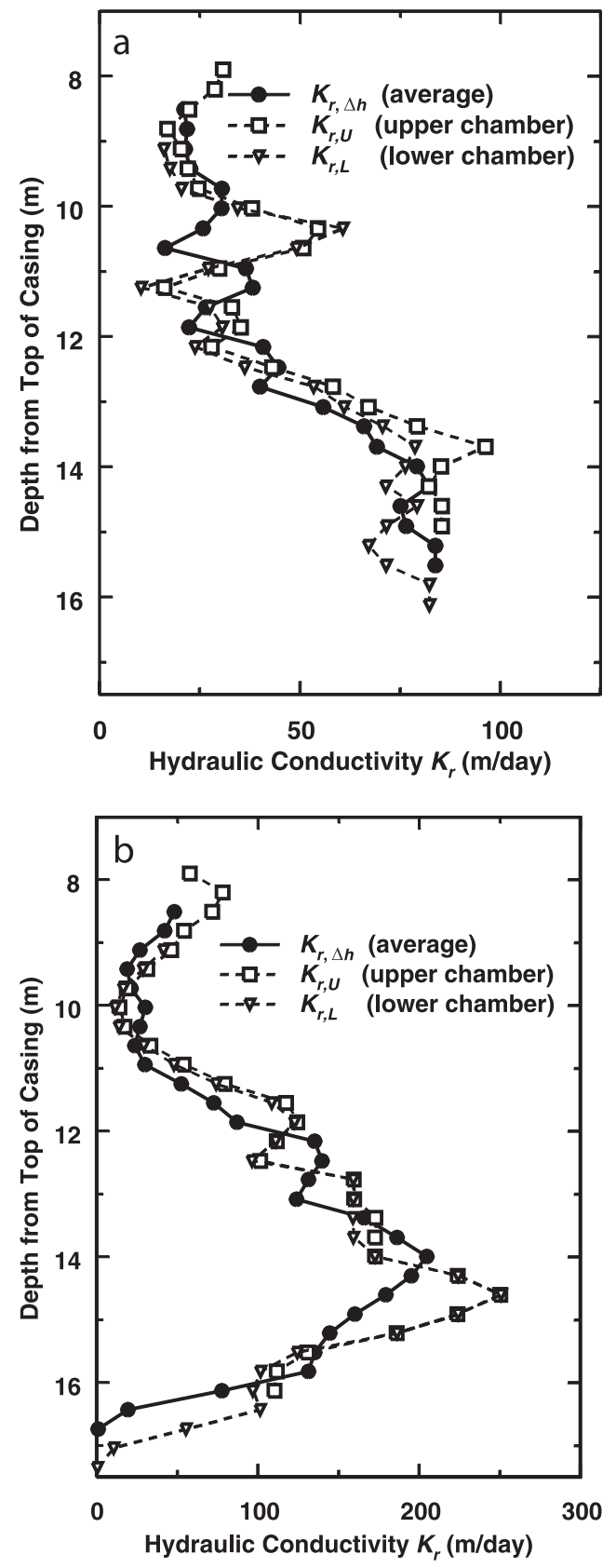

Figure 2. Comparison of $K_{r}$ profiles obtained from the DFT analyzed using the head difference and by-chamber interpretations: (a) well 14 and (b) well 15.

regression equations shown on these plots indicate high correlation coefficients $(R)$ between both estimates $\left(R^{2}=\right.$ 0.97 for well 14 and $R^{2}>0.99$ for well 15$)$. Note that the $95 \%$-confidence bands are narrow, and that there are no outliers. Identical test scales, i.e., screen lengths, are obviously critical for this relationship.

[50] Three $K_{r}$ estimates provide sufficient data to test the self-consistency of the DFT. In spite of the different support volumes, the similarity between the data from two different by-chamber interpretations is an indicator of the conceptual and technical validity of the test. This DFT trait is unique among the single-borehole tests. Data from either chamber can be used to characterize the $K_{r}$ distribution. We select the 

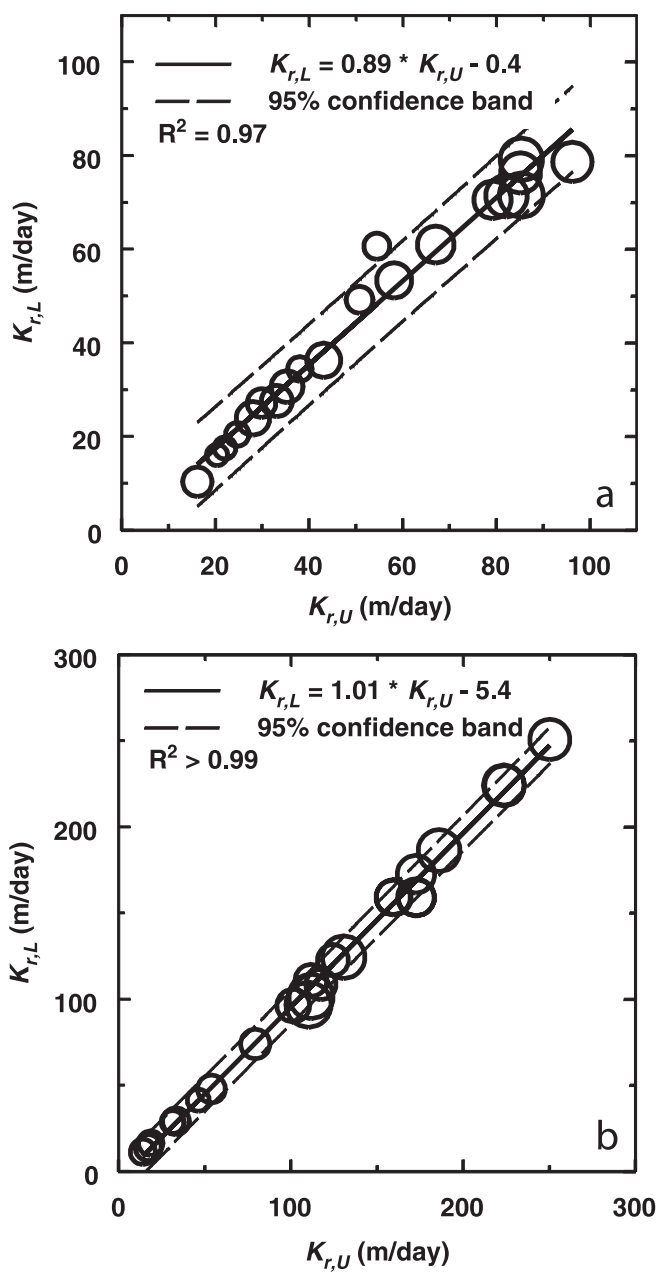

Figure 3. Correlation between $K_{r}$ data from the DFT bychamber interpretations using the upper and lower DFT chambers data: (a) well 14 and (b) well 15. Symbol size increases with depth of test.

$K_{r, U}$ data for use as a reference for comparison with the other techniques.

\subsection{MLST Data}

[51] The dimensions of the MLST are shown in Figure 1b. At each depth, interpretation of $K_{r}$ was performed as described in section 2.2. Figure 4 shows vertical profiles of $K_{r}$ for both wells. For comparison, the DFT data $\left(K_{r, U}\right)$ are also included. Both data interpretations assumed local aquifer isotropy. The similarity of these profiles is striking.

[52] The self-consistency test is not available for the MLST, and thus we apply the DFT data as a benchmark for this data analysis. The scatterplots and regression equations of the correlation between $K_{r}$ from the MLST and $K_{r, U}$ from the DFT in Figure 5 indicate remarkably narrow $95 \%$ confidence bands and a very strong correlation between the data from both techniques $\left(R^{2}=0.98\right.$ for well 14 and $R^{2}=$ 0.96 for well 15 ). This similarity between data from the two techniques has practical ramifications: selection of hydraulic technique for a given measurement scale - screen length becomes a matter of practical consideration only.

\subsection{BFT Data}

[53] The dimensions of the BFT are shown in Figure 1c. During the field tests, the elevation increments between the two consecutive vertical positions were $30 \mathrm{~cm}$, and the locations of the center of each interval coincided with either the location of the center of the DFT chamber, or a central packer that were used in the DFT. An averaging interval of $60 \mathrm{~cm}$ was used for analysis of the cumulative discharge curve to provide consistency between the BFT and DFT. It is important to note that the multiple BFTs at the time of the experiment indicated an absence of ambient flow within the detection limits, i.e. $q(z)=0$.

[54] Due to the very low drawdown induced by pumping during the BFT, the depth-averaged $K_{\text {rave }}$ in equation (8) could not be estimated independently. As is commonly done
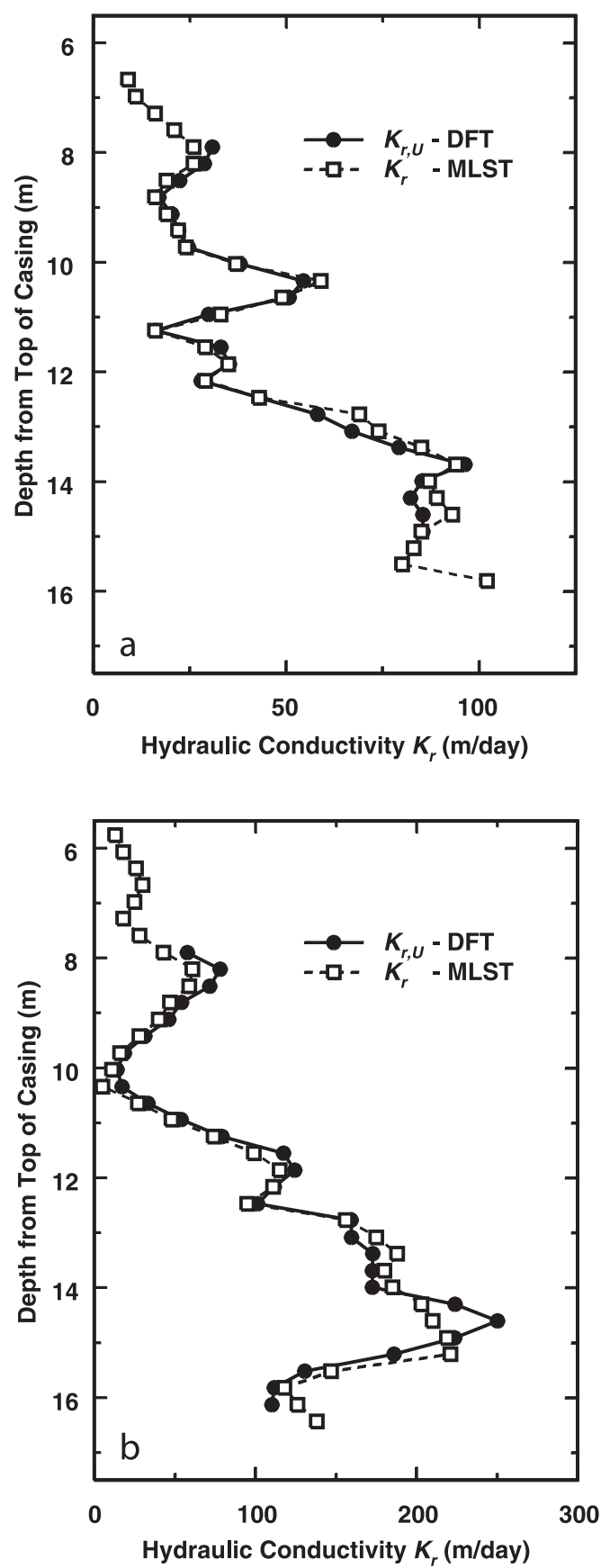

Figure 4. Comparison of $K_{r}$ profiles obtained from the DFT and MLST: (a) well 14 and (b) well 15. 

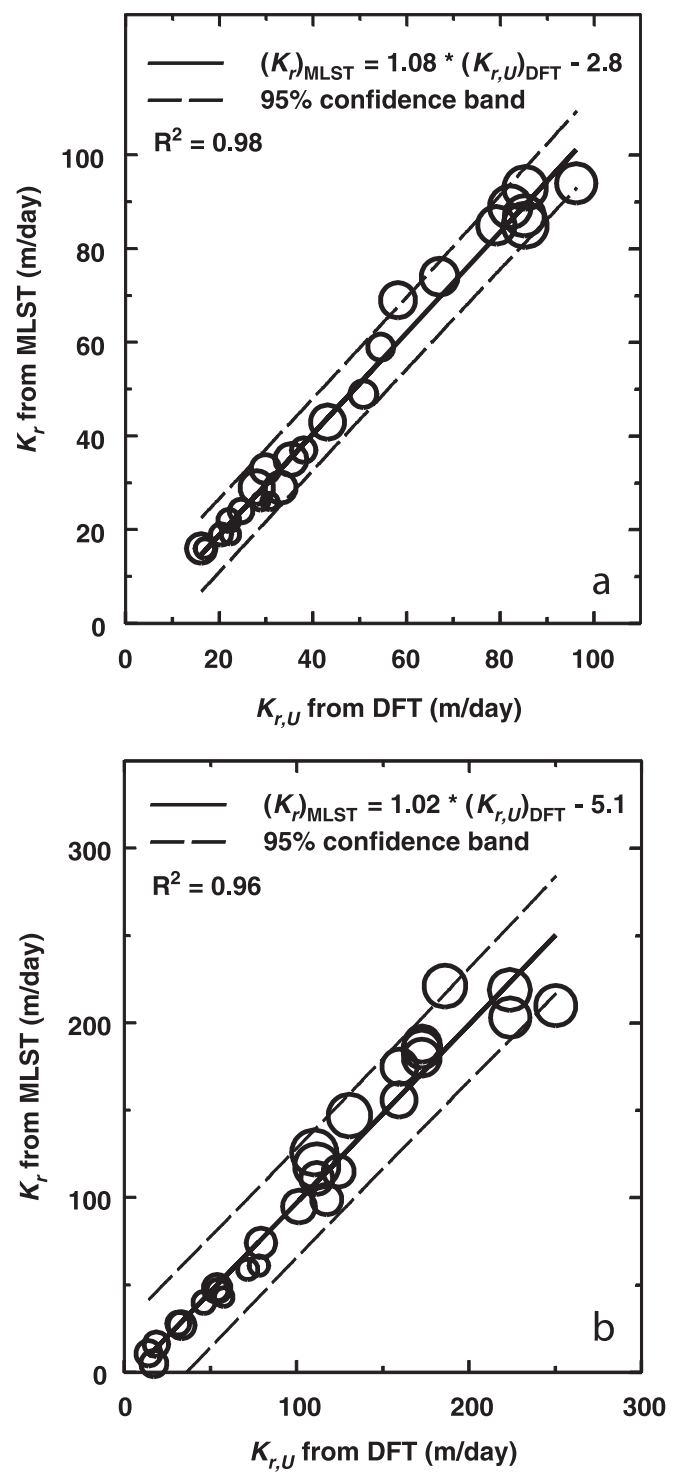

Figure 5. Correlation between the $K_{r}$ data from the DFT and the MLST: (a) well 14 and (b) well 15. Symbol size increases with depth of test.

in practice (pumping tests, etc.), to eliminate any dependence of the BFT interpretation on other techniques we evaluate normalized vertical profiles of $K_{r, i} / K_{r, \text { ave }}$ from equation (8) using the BFT data for wells 14 and 15 (Figure 6). For comparison purposes, the normalized DFT data $\left(K_{r, U}\right)$ are plotted Figure 6 also; in this case depthaveraged $K_{r, U \text {,ave }}$ is calculated using only the DFT data.

[55] The DFT and BFT data exhibit similar small-scale trends of $K_{r}$. On a larger scale, the trends of the two tests differ slightly; the BFT overestimates $K_{r}$ at smaller depths and underestimates $K_{r}$ at larger depths. The range of $K_{r}$ from the DFT is broader than that from the BFT.

[56] The scatterplots and the regression equations shown on Figure 7 exhibit a lower correlation between the BFT data and other methods, which are capable of physical isolating the tested intervals. These plots exhibit wider $95 \%$-confidence bands and reduced correlation coefficients $\left(R^{2}=0.59\right.$ in well 14 and $R^{2}=0.7$ in well 15$)$.
[57] Unlike the DFT and MLST, the BFT is not affected by anisotropy. In an attempt to improve the match between BFT and DFT, one could reinterpret the $K_{r}$ profiles from the DFT using assumed anisotropy values of $a>1$ [see Kabala, 2000]. As was previously shown by Zlotnik [1994], Zlotnik and Ledder [1996], and Zlotnik and Zurbuchen [2000], such correction leads to a uniform increase of $K_{r}$ data from DFT without improving the match between BFT and other techniques.

[58] Other sources of discrepancy between the BFT and other tests include the differences in support volume (averaging mechanisms) and/or violation of the commonly accepted assumptions for data interpretation. In the following discussion, we concentrate on the effects of the support

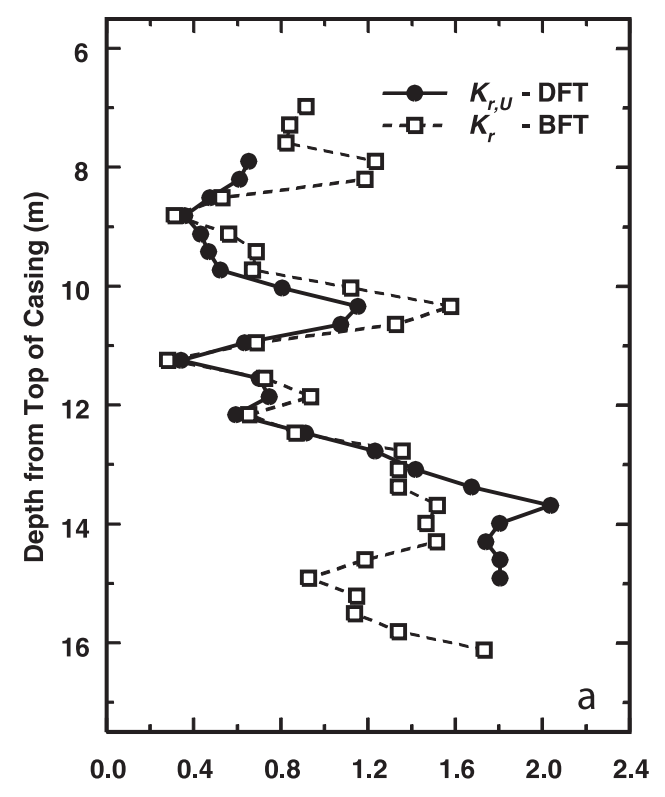

Normalized Hydraulic Conductivity $K_{r} / K_{r, a v e}$

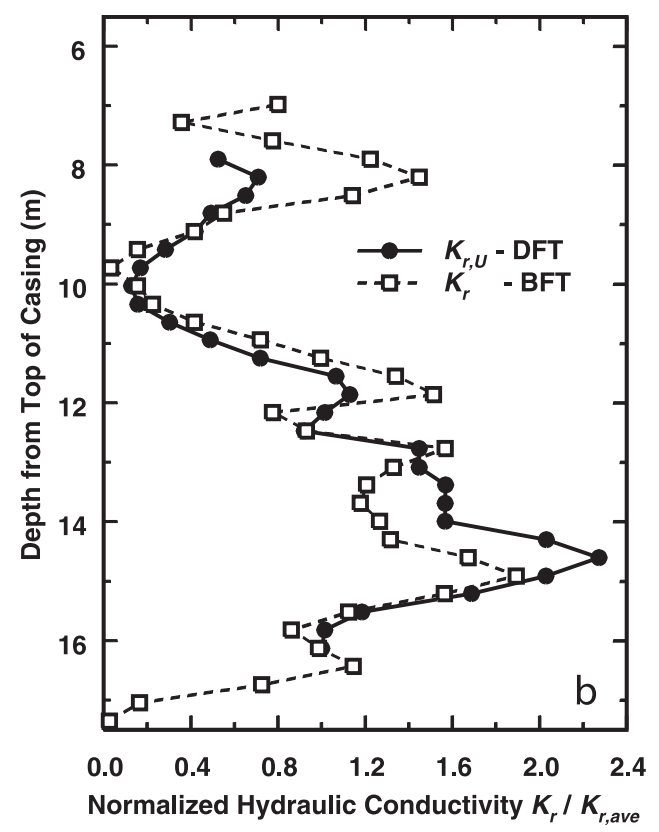

Figure 6. Comparison of $K_{r}$ profiles obtained from the BFT and DFT: (a) well 14 and (b) well 15. 

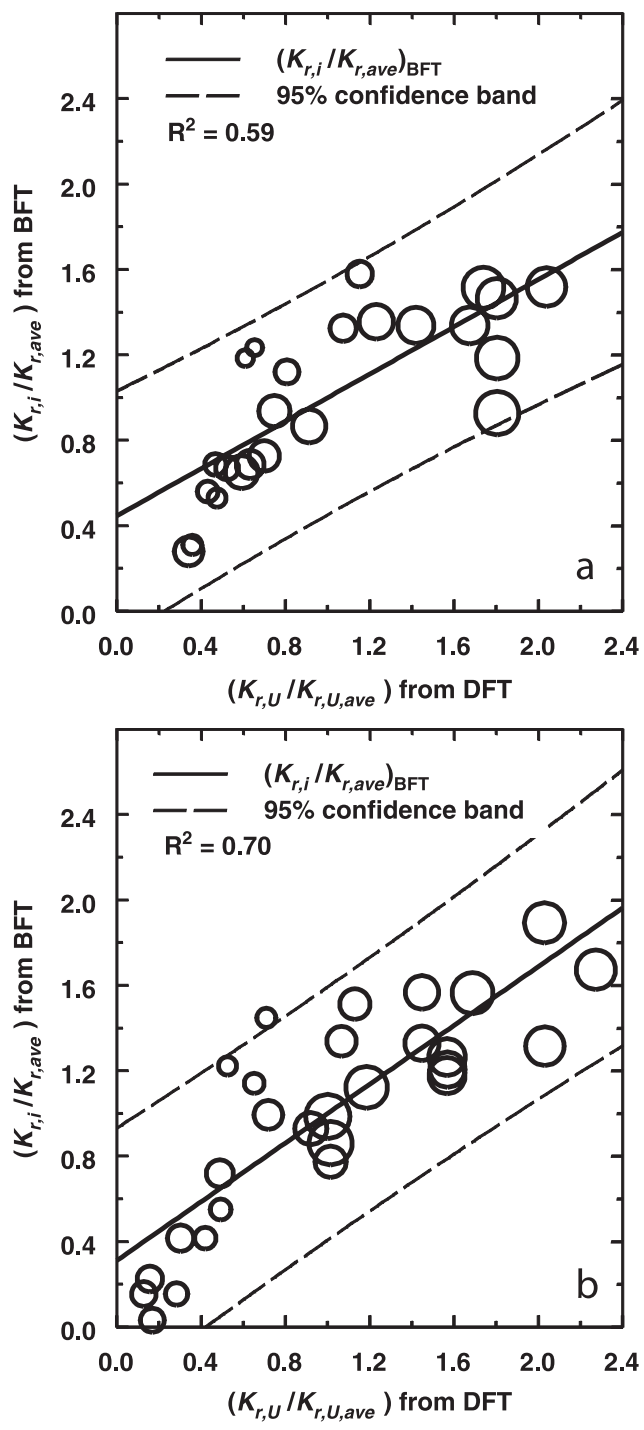

Figure 7. Correlation between the $K_{r}$ data from the BFT and the DFT: (a) well 14, $\left(K_{r, i} / K_{r, a v e}\right)_{B F T}=0.55\left(K_{r, U} /\right.$ $\left.K_{r, U, a v e}\right)_{D F T}+0.45$, and (b) well $15,\left(K_{r, i} / K_{r, \text { ave }}\right)_{B F T}=0.69$ $\left(K_{r, U} / K_{r, U, a v e}\right)_{D F T}+0.69$. Symbol size increases with depth of test. volume, assuming that our test design and data interpretation methods are valid.

\subsection{Summary Statistics}

[59] Analysis of experimental data on scale effect and scale invariance in $K_{r}$ and $\ln K_{r}$ can be facilitated greatly by the presentation of $K_{r}$ statistics [Zlotnik et al., 2000]. Considering a relatively small data set, only the range, mean, standard deviation, and skewness for single-well and two-well data sets are given in Table 1.

[60] Figures 3, 5, and 7 show the overall upward trend of decreasing $K_{r}$. Comparison of the mean $K_{r}$ for wells 14 and 15 clearly indicates that the assumption of a perfectly stratified aquifer on the horizontal scale of interwell distance is not a good approximation.

[61] At the same time, the standard deviation of $K_{r}$ and $\ln$ $K_{r}$ is similar for all methods. This result differs from common notions that among field hydraulic tests the BFT detects the highest variability in $K_{r}$, or that the accuracy of this method is most suitable for aquifer characterization [e.g., Hess et al., 1992; Rehfeldt et al., 1992]. It is apparent that test scale is a critical factor that determines the standard deviation (or variance) in $K_{r}$.

[62] Table 1 indicates that the distributions of $K_{r}$ and $\ln$ $K_{r}$ in wells 14 and 15 from the DFT and MLST are more positively skewed, when compared to the BFT data. This observation is also supported by visual inspection of Figures 5 and 7.

\section{Discussion of Averaging Mechanisms}

[63] Similarities between the DFT and MLST data and their discrepancies with the BFT data in heterogeneous media can be explained in part by the averaging volume effects. Desbarats [1992, 1993, 1994] proposed the functional form of the weighting function after conducting numerical studies of two-dimensional nonuniform steady state flow in a heterogeneous media. This function was proportional to the squared inverse distance from the pumping well, which is identical to the squared magnitude of the mean local velocity. Oliver [1993, p. 169] derived a similar functional form of the weighting function. Zlotnik and Ledder [1996, p. 1127] suggested that the spatial distribution of the magnitude of velocity is a good indicator

Table 1. Statistics of $K_{r}$

\begin{tabular}{|c|c|c|c|c|c|c|c|c|c|}
\hline \multirow[b]{2}{*}{ Characteristics } & \multicolumn{3}{|c|}{ Well 14} & \multicolumn{3}{|c|}{ Well 15} & \multicolumn{3}{|c|}{ Both Wells } \\
\hline & DFT & MLST & $\mathrm{BFT}^{\mathrm{a}}$ & DFT & MLST & $\mathrm{BFT}^{\mathrm{a}}$ & DFT & MLST & $\mathrm{BFT}^{\mathrm{a}}$ \\
\hline Number of samples & 24 & 24 & 24 & 28 & 28 & 28 & 52 & 52 & 52 \\
\hline Minimum $K_{r}, \mathrm{~m} / \mathrm{d}$ & 16 & 16 & 13 & 14 & 5 & 3.5 & 14 & 5 & 3.5 \\
\hline Minimum $\ln K_{r}, \mathrm{~m} / \mathrm{d}$ & 2.79 & 2.77 & 2.58 & 2.65 & 1.61 & 1.26 & 2.65 & 1.61 & 1.26 \\
\hline Maximum $K_{r}, \mathrm{~m} / \mathrm{d}$ & 96 & 94 & 75 & 250 & 221 & 209 & 250 & 221 & 209 \\
\hline Maximum $\ln K_{r}, \mathrm{~m} / \mathrm{d}$ & 4.57 & 4.54 & 4.31 & 5.52 & 5.40 & 5.34 & 5.52 & 5.40 & 5.34 \\
\hline Mean $K_{r}, \mathrm{~m} / \mathrm{d}$ & 47 & 48 & 47 & 110 & 107 & 110 & 81 & 80 & 81 \\
\hline Geometric mean of $K_{r}, \mathrm{~m} / \mathrm{d}$ & 41 & 40 & 43 & 86 & 77 & 86 & 61 & 57 & 62 \\
\hline Mean of $\ln K_{r}, \mathrm{~m} / \mathrm{d}$ & 3.71 & 3.70 & 3.76 & 4.45 & 4.34 & 4.45 & 4.11 & 4.05 & 4.13 \\
\hline Standard Deviation of $K_{r}, \mathrm{~m} / \mathrm{d}$ & 26 & 28 & 19 & 68 & 71 & 56 & 61 & 62 & 53 \\
\hline Standard Deviation of $\ln K_{r}, \mathrm{~m} / \mathrm{d}$ & 0.57 & 0.62 & 0.49 & 0.81 & 0.98 & 0.92 & 0.79 & 0.89 & 0.82 \\
\hline Skewness of $K_{r}, \mathrm{~m} / \mathrm{d}$ & 0.59 & 0.51 & -0.22 & 0.37 & 0.19 & -0.41 & 1.07 & 0.92 & 0.60 \\
\hline Skewness of $\ln K_{r}, \mathrm{~m} / \mathrm{d}$ & 0.06 & 0.06 & -0.99 & -0.82 & -1.12 & -2.00 & -0.07 & -0.37 & -0.96 \\
\hline
\end{tabular}

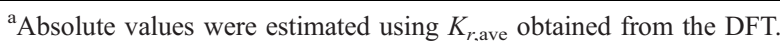




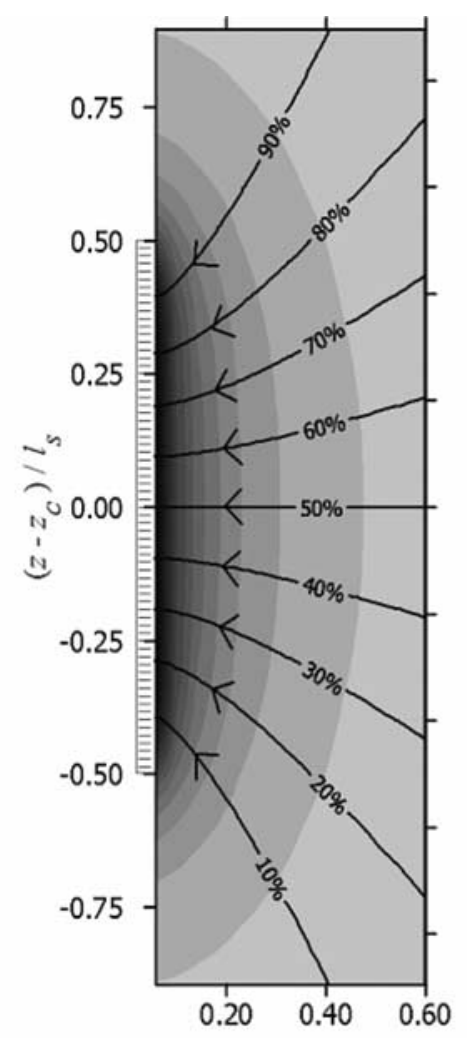

Radial Distance from Well Axis ( $m$ )

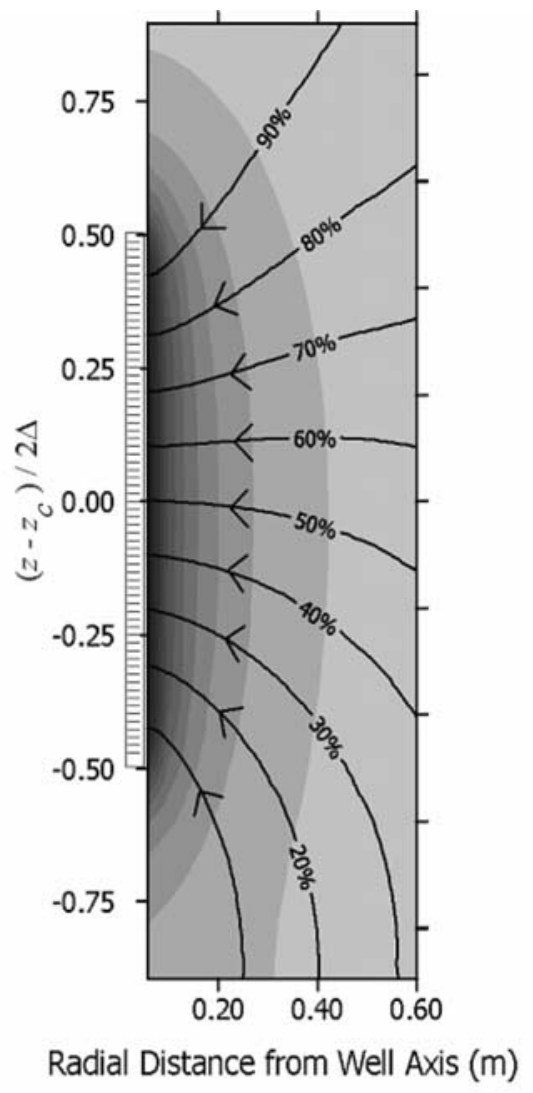

(b)

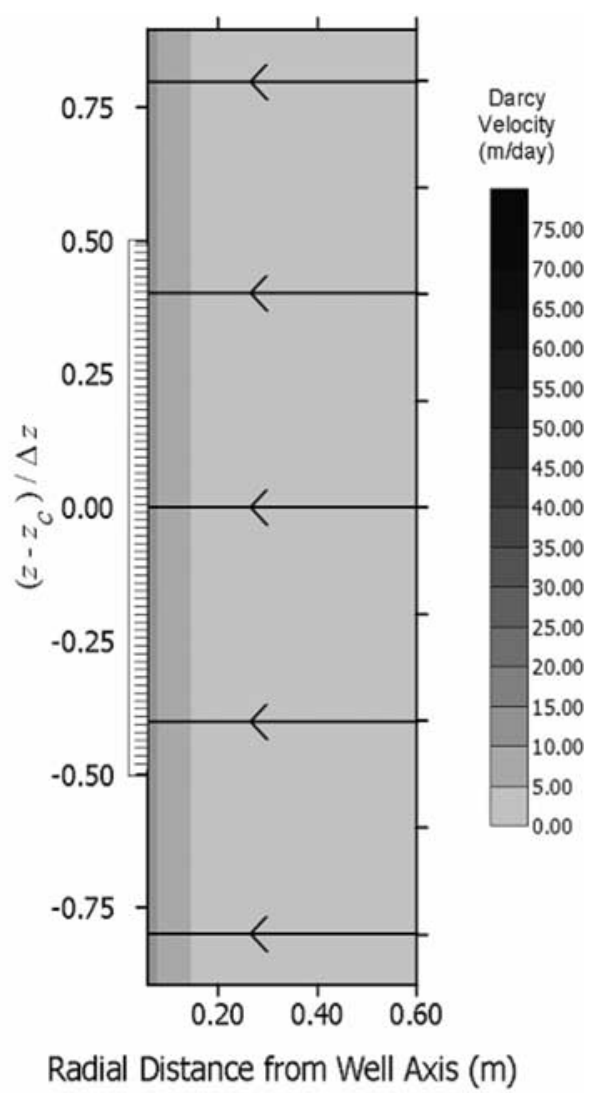

(c)

Figure 8. Velocity magnitude and streamlines near well in the uniform aquifer in single-borehole tests: (a) MLST, (b) DFT (distribution near the upper chamber only is shown; note the magnitude trend toward the central packer), and (c) BFT. Here vertical coordinate is normalized by the characteristic scale of each instrument and varies from -0.5 to 0.5 along the tested screen section; $z_{\mathrm{c}}$ is elevation of the instrument center.

of averaging mechanisms of the DFT. Tartakovsky et al. [2000, p. 2440] applied this concept for investigation of the air permeameter. Using other arguments, Molz et al. [2000] proposed the squared velocity magnitude as the universal weighting function for various systems.

[64] Since the linear dimension of the instrument determines the local velocity near the instrument, this dimension can be used as a linear scale for the support volume, or the zone with the highest weight of $K_{r}$ that is interrogated by a single-borehole test. Using the parameters of our instruments, we will generate the distributions of instantaneous local velocity magnitude in a uniform media and explore the plausibility of the hypothesis of a velocity-based weighting function.

[65] The magnitude of velocity in the vicinity of the MLST interval (Figure 8a) was plotted using head distribution near the linear source [Bear, 1979, p. 346]. The vertical coordinate centered in the middle of the tested interval $\left(z_{c}\right)$ was normalized as $\left(z-z_{c}\right) / l_{s}$. Zones near the screen must be assigned the highest values of the velocity-based weighting function, which vanishes at large distances from the screen due to the divergence of the flow field.

[66] Velocity magnitude for the steady state DFT was obtained by superposition of a line source and a line sink that are separated by a packed interval (Figure $8 b$ ). Here only the upper chamber (sink) is shown because of mirror symmetry. The vertical coordinate centered in the middle of the upper chamber $\left(z_{c}\right)$ was normalized as $\left(z-z_{c}\right) /(2 \Delta)$. The highest weight should be assigned to the zone near the chamber screen. Near the central packer, the velocity magnitude is barely noticeable even though streamlines indicate that flow occurs between chambers. The similarity of the velocity fields and velocity-based weighting functions of the DFT and MLST explains the similarity of $K_{r}$ estimates from the DFT by-chamber interpretation and the MLST.

[67] Figure 8b also indicates the DFT's insensitivity to anisotropy $a^{2}=K_{r} / K_{z}$ at the scale of the DP length. In spite of significant vertical flow between chambers, the weighting function is large in the near-screen zone of predominantly horizontal flow and too small in the vertical flow zone. Experiments by Hvilshøj et al. [2000] also confirmed this weak DFT sensitivity to anisotropy effects.

[68] The BFT-induced axially convergent horizontal flow in a fully penetrating well is shown in Figure 8c [Javandel and Witherspoon, 1969]. The vertical coordinate centered in the middle of averaging interval $\left(z_{c}\right)$ is normalized as $\left(z-z_{c}\right) / \Delta z$. In comparison to the more "localized" DFT and MLST flow systems, the velocity-based weighting function is more uniform in the vertical direction compared. The discrepancies between the BFT and other tests can be 
attributed to either the averaging mechanism or violation of the assumptions for the BFT data analysis (e.g., imperfect aquifer stratification, head losses, etc.).

[69] Velocity distributions in a uniform media can be considered as zero-order approximations for velocity in a weakly heterogeneous formation [e.g., Indelman and Zlot$n i k, 1996]$. Consistent analysis of averaging mechanisms for different tests would require three-dimensional generalization of previous work to transient nonuniform flow in heterogeneous formations. However, these issues are beyond the scope of our experimental study.

\section{Conclusions}

[70] Estimation of hydraulic conductivity $K_{r}$ from a field hydraulic test in a heterogeneous formation can be interpreted as an averaging procedure associated with the testing instrument. This averaging is defined by the convergent/ divergent flow system in the vicinity of the instrument. An analysis of flow systems indicates that the spatial distributions of the magnitude of instantaneous velocity may have a strong bearing on the support volumes and the magnitude of the weighting functions. The linear dimensions of the instruments are important factors affecting these spatial distributions. Therefore these dimensions can be applied for analyses of various single-borehole methods to reconcile previously proposed ad-hoc approaches [cf. Guyonet et al., 1993; Eggleston et al., 1996; Zlotnik and Ledder, 1996].

[71] We designed a field experiment for comparing three single-borehole hydraulic testing techniques (DFT, MLST, and BFT) that are based on different kinematic flow structures and different shapes and sizes of the support volume. All experiments were performed with an identical linear scale. For the DFT and MLST, the test scale was the tested screen interval. In the case of the BFT this scale was not apparent, and a "surrogate" scale, the vertical flow averaging interval, was selected for data interpretation. The strongly convergent/divergent flow systems of the DFT or MLST suggest a higher weight of the nearscreen zone as compared to the BFT, which has a more uniform distribution of the velocity magnitude along the well screen.

[72] Data on the vertical distribution of $K_{r}$ were collected in two wells in a heterogeneous alluvial aquifer with $K_{r}$ as high as $260 \mathrm{~m} /$ day. Linear regression analysis, which was used for intertechnique comparison, indicates a strong correlation between the data from the three methodologies in spite of their differences. Correlation of $K_{r}$ estimates obtained from the DFT and MLST that have similar intrinsic physical scale, tested screen interval, is higher than between either of these two methods and the BFT. Note that various hydraulic tests for estimating $K_{r}$ yield similar standard deviations if similar instrument dimensions are chosen. This conclusion differs from the common notion that data from the BFT exhibit the highest variability in $K_{r}$ among field hydraulic tests. For intertechnique comparisons in heterogeneous formations, the instrument dimensions are paramount.

[73] Several technical conclusions follow from this study:

[74] 1. The DFT has the capability to verify self-consistency in characterizing vertical aquifer heterogeneity. The by-chamber interpretation enhances the resolution of heter- ogeneous $K_{r}$ as compared to the head difference interpretation, and the data from either chamber can be used for characterization of aquifer heterogeneity.

[75] 2. The strong correlation between the DFT and MLST results indicates that an equivalent accuracy of $K_{r}$ estimates can be achieved if proper instrument dimensions are chosen. Technical convenience should be the primary consideration when choosing between these tests.

[76] 3. The BFT stands apart from other tests because in the absence of a natural linear vertical scale, only the surrogate scale (the vertical averaging window) can be used as a predictor of the support volume.

[77] Our field study highlights the role of these instruments and physical averaging mechanisms in estimating $K$ and the concept of the weighting function in heterogeneous aquifers. Averaging volume effects could explain the differences observed with the instruments. Experimental data support the explanation of the role of the screen length as an indicator of support volume, but the effects of the various instruments have not been quantified. Further studies of averaging mechanisms and weighting functions will require intensive three-dimensional high-resolution numerical simulations of transient nonuniform flow for linear scales over several orders of magnitude.

[78] Acknowledgments. This work was supported by the USGS grant HQ96GR02683, Water Center and Department of Geosciences, University of Nebraska-Lincoln (UNL). We are grateful to Fred Molz, Clemson University, and John Wilson, New Mexico Institute of Mining and Technology, for sharing their work on weighting functions, to Daniel Tartakovsky, Los Alamos National Laboratory, for discussions, to Dean Eisenhauer, UNL, for verification of the DP pump calibration, to Jim Butler, Kansas Geological Survey, for applying our methodology and equipment at the GEMS site, Alex Desbarats, Geological Survey of Canada, for review of the early version of the manuscript, and Charles Flowerday and Edwin Harwey, UNL, for manuscript editing. We thank Dr. William G. Gray, Editor, the Associate Editor, and two anonymous reviewers for in-depth and detailed reviews that lead to significant improvements of this manuscript.

\section{References}

Baveye, P., and G. Sposito, The operational significance of the continuum hypothesis in the theory of water movement through soil and aquifers, Water Resour. Res., 20(5), 521-530, 1984.

Bear, J., Hydraulics of Groundwater, McGraw-Hill, New York, 1979.

Beckie, R., Measurement scale, network sampling scale, and groundwater model parameters, Water Resour. Res., 32(1), 65-76, 1996.

Beckie, R., A comparison of methods to determine measurements support volumes, Water Resour. Res., 37(14), 925-936, 2001.

Beckie, R., and B. Wang, A numerical method to characterize the averaging process invoked by a slug test: in Computational Methods in Water Resources X, edited by A. Peters et al., pp. 703-710, Kluwer Acad., Norwell, Mass., 1994.

Boman, G. K., F. J. Molz, and K. D. Boone, Borehole flowmeter application in fluvial sediments: Methodology, results, and assessment, Ground Water, 35(3), 443-450, 1997.

Bouwer, H., and R. C. Rice, A slug test for determining hydraulic conductivity of unconfined aquifers with completely or partially penetrating wells, Water Resour. Res., 12(3), 423-428, 1976.

Brace, W. F., Permeability of crystalline rocks: New measurements, J. Geophys. Res., 89, 4327-4330, 1984.

Butler, J. J., Jr., Design, Performance, and Analysis of Slug Tests, A. F. Lewis, New York, 1997.

Clauser, C., Permeability of crystalline rocks, Eos Trans. AGU, 73(21), 233, 1992.

Cole, K., and V. Zlotnik, Modification of Dagan's numerical method for slug and packer test interpretation, in Computational Methods in Water Resources X, edited by A. Peters et al., pp. 719-726, Kluwer Acad., Norwell, Mass., 1994. 
Cushman, J. H., On unifying the concepts of scale, instrumentation, and stochastics in the development of multiphase transport theory, Water Resour. Res., 20(11), 1676-1688, 1984.

Dagan, G., Flow and Transport in Porous Formations, Springer-Verlag, New York, 1989.

Desbarats, A. J., Spatial averaging of transmissivity in heterogeneous fields with flow toward a well, Water Resour. Res., 28(3), 757-767, 1992.

Desbarats, A. J., Geostatistical analysis of interwell transmissivity in heterogeneous aquifers, Water Resour. Res., 29(4), 1239-1246, 1993.

Desbarats, A. J., Spatial averaging of hydraulic conductivity under radial flow conditions, Math. Geol., 26(1), 1-21, 1994.

Dinwiddie, C. L., N. A. Foley, and F. J. Molz, In-well hydraulics of the electromagnetic borehole flowmeter, Ground Water, 37(2), 305-315, 1999.

Eggleston, J. R., and S. A. Rojstacher, Can we predict mass transport?, Environ. Sci. Technol., 34(8), 4010-4017, 2000.

Eggleston, J. R., S. A. Rojstacher, and J. J. Pierce, Identification of hydraulic conductivity structure in sand and gravel aquifers: Cape Cod data set, Water Resour. Res., 32(5), 1209-1222, 1996.

Guyonet, D., S. Mishra, and J. McCord, Evaluating the volume of porous medium investigated during slug tests, Ground Water, 31(4), 627-634, 1993.

Hess, K. M., S. H. Wolf, and M. A. Celia, Large-scale natural gradient tracer test in sand and gravel, Cape Cod, Massachusetts: 3. Hydraulic conductivity variability and calculated macrodispersivities, Water Resour Res., 28(10), 2011-2027, 1992

Hubbard, S. S., and Y. Rubin, Hydrogeological parameter estimation using geophysical data: A review of selected techniques, J. Contam. Hydrol. $45,3-34,2000$

Hvilshøj, S., K. H. Jensen, and B. Madsen, Single-well dipole flow tests: Parameter estimation and field testing, Ground Water, 38, 53-62, 2000

Hyndman, D. W., and S. M. Gorelick, Estimating lithological transport properties in three dimensions using seismic and tracer data: The Kesterton Aquifer, Water Resour. Res., 32(9), 2659-2670, 1996.

Indelman, P., and V. Zlotnik, Average nonuniform flow in stratified heterogeneous formations, Water Resour. Res., 33(5), 927-934, 1997.

Javandel, I., and P. A. Witherspoon, A method of analyzing transient fluid flow in multilayered aquifers, Water Resour. Res., 5(4), 856-869, 1969.

Kabala, Z. J., The dipole flow test: A new single-borehole test for aquifer characterization, Water Resour. Res., 29(1), 99-107, 1993.

Kabala, Z. J., "Dipole probe: design and field applications of a singleborehole device for measurements of vertical variations of hydraulic conductivity" by Vitaly A. Zlotnik and Brian R. Zurbuchen, Discussion, Ground Water, 38, 162-163, 2000.

McElwee, C., and M. A. Zenner, A non-linear model for analysis of slugtest data, Water Resour. Res., 34(1), 55-66, 1998

Melville, J. G., F. J. Molz, O. Guven, and M. A. Widdowson, Multilevel slug tests with comparisons to tracer data, Ground Water, 29(6), 897907, 1991.

Molz, F. J., R. H. Morin, A. E. Hess, J. G. Melville, and O. Guven, The impeller meter for measuring aquifer permeability variations: Evaluation and comparison with other tests, Water Resour. Res., 25(7), 1677-1683, 1989.

Molz, F. J., G. K. Boman, S. C. Young, and W. R. Waldrop, Borehole flowmeters: Field applications and data analysis, J. Hydrol., 163, $347-$ $371,1994$.

Molz, F. J., C. L. Dinwiddie, and J. L. Wilson, Development of a physical basis for calculating spatial weighting functions, with application to the gas minipermeameter, Eos Trans. $A G U, 81(48)$, Fall Meet. Suppl., abstract H51D-10, 2000.

Oliver, D. S., The averaging process in permeability estimation from welltest data, SPE Form. Eval., 5, 319-324, 1990.

Oliver, D. S., The influence of non-uniform transmissivity and storativity on drawdown, Water Resour. Res., 29(1), 169-178, 1993

Ptak, T., and G. Teutsch, Forced and natural gradient tracer tests in a highly heterogeneous porous aquifer: Instrumentation and measurements, J. Hydrol., 159, 79-104, 1994.

Rehfeldt, K. R., P. Hufschmied, L. W. Gelhar, and M. E. Schaefer, The borehole flowmeter technique for measuring hydraulic conductivity variability, Rep. EN 6511, Electric Power Res. Inst., Palo Alto, Calif., 1989.

Rehfeldt, K. R., J. M. Boggs, and L. W. Gelhar, Field study of dispersion in a heterogeneous aquifer, 3, Geostatistical analysis of hydraulic conductivity, Water Resour. Res., 28(12), 3309-3324, 1992

Ruud, N. C., and Z. J. Kabala, Numerical evaluation of the flowmeter test in a layered aquifer with a skin zone, J. Hydrol., 203, 101-108, 1997.
Ruud, N. C., Z. J. Kabala, and F. J. Molz, Evaluation of flowmeter-head loss effects in the flowmeter test, J. Hydrol., 224, 55-63, 1999.

Schulze-Makuch, D., and D. S. Cherkauer, Variations in hydraulic conductivity with scale of measurements during aquifer tests in heterogeneous, porous carbonate rocks, Hydrogeol. J., 6(2), 204-215, 1998.

Spalding, R. F., and M. E. Exner, Areal, vertical, and temporal differences in ground water chemistry: 1. Inorganic constituents, J. Environ. Qual., 9(3), 466-478, 1980.

Springer, R. K., Application of an improved slug test analysis to the largescale characterization of heterogeneity in a Cape Cod aquifer, M.S. thesis, 162 pp., Dep. of Civ Eng., Mass. Inst. of Technol., Cambridge, Mass., 1991.

Springer, R. K., and L. W. Gelhar, Characterization of large scale aquifer heterogeneity in glacial outwash by analysis of slug tests with oscillatory response, Cape Cod, Massachusetts, in Toxic Substances Hydrology Program, Proceeding of the Technical Meeting, Monterey, California, March $11-15,1991$, edited by G. Mallard and D. Aronson, U.S. Geol. Surv. Water Resour. Invest. Rep., 91-4034, 36-40, 1991.

Streltsova, T. D., Well Testing in Heterogeneous Formations, John Wiley, New York, 1988.

Sutton, D. J., Z. J. Kabala, D. E. Schaad, and N. C. Ruud, The dipole-flow test with a tracer: A new single-borehole tracer test for aquifer characterization, J. Contam. Hydrol., 44, 71-101, 2000.

Tartakovsky, D. M., J. D. Moulton, and V. A. Zlotnik, Kinematic structure of minipermeameter flow, Water Resour. Res., 36(9), 2433-2442, 2000.

Taylor, K., and F. Molz, Determination of hydraulic conductivity and porosity logs in wells with a disturbed annulus, J. Contam. Hydrol., 5, 317332, 1990

Taylor, K., S. Wheatcraft, J. Hess, J. Hayworth, and F. Molz, Evaluation of methods for determining the vertical distribution of hydraulic conductivity, Ground Water, 28(1), 89-98, 1990.

Tidwell, V. C., A. L. Gutjahr, and J. L. Wilson, What does an instrument measure? Empirical spatial weighting functions calculated from permeability data sets measured on multiple sample supports, Water Resour. Res., 35(1), 43-54, 1999.

Zlotnik, V., Interpretation of slug and packer tests in anisotropic aquifers, Ground Water, 32, 761-766, 1994.

Zlotnik, V., and G. Ledder, Effect of boundary conditions on dipole flow, in Computational Methods in Water Resources X, vol. 2, edited by A. Peters et al., pp. 907-914, Kluwer Acad., Norwell, Mass., 1994.

Zlotnik, V., and G. Ledder, Theory of dipole flow in uniform anisotropic aquifers, Water Resour. Res., 32(4), 1119-1128, 1996.

Zlotnik, V. A., and V. L. McGuire, Multi-level slug tests in highly permeable formations: 1. Modification of the Springer-Gelhar (SG) model, J. Hydrol., 204, 271-282, 1998a.

Zlotnik, V. A., and V. L. McGuire, Multi-level slug tests in highly permeable formations: 2 . Hydraulic conductivity identification, method verification, and field applications, J. Hydrol., 204, 283-296, 1998b.

Zlotnik, V. A., and B. R. Zurbuchen, Dipole probe: Design and field applications of a single-borehole device for measurements of vertical variations of hydraulic conductivity, Ground Water, 36, 884-893, 1998.

Zlotnik, V. A., and B. R. Zurbuchen, "Dipole probe: design and field applications of a single-borehole device for measurements of vertical variations of hydraulic conductivity" by Vitaly A. Zlotnik and Brian R. Zurbuchen, Discussion, Ground Water, 38, 163-165, 2000.

Zlotnik, V. A., R. F. Zurbuchen, T. Ptak, and G. Teutsch, Support volume and scale effect in hydraulic conductivity: experimental aspects, in Theory, Modeling, and Field Investigation in Hydrogeology: A Special Volume in Honor of Shlomo P. Neuman's 60th Birthday, edited by D. Zhang and C. L. Winter, Spec. Pap. Geol. Soc. Am., 348, 215-231, 2000

Zlotnik, V. A., B. R. Zurbuchen, and T. Ptak, The steady-state dipole-flow test for characterization of hydraulic conductivity statistics in a highly permeable aquifer: Horkheimer Insel site, Germany, Ground Water, 39, 504-516, 2001

Zurbuchen, B. R., V. A. Zlotnik, and J. J. Butler Jr., Dynamic interpretation of slug tests in highly permeable aquifers, Water Resour. Res., 38(3), 1025, doi:10.1029/20001WR00354, 2002.

V. A. Zlotnik, Department of Geosciences, University of Nebraska at Lincoln, Lincoln, NE 68588, USA. (vzlotnik@unl.edu)

B. R. Zurbuchen, Nebraska Department of Environmental Quality, 1200 N Street, Lincoln, NE 68509, USA. 